\title{
BMJ Open Effect of promoting current local research activities on large monitors on the population's interest in health- related research: a randomised controlled trial
}

\author{
Ronny Gunnarsson, ${ }^{\oplus 1,2}$ Paul Cullen, ${ }^{3,4}$ Clare Heal, ${ }^{4}$ Jennifer Banks ${ }^{4}$
}

To cite: Gunnarsson $\mathrm{R}$, Cullen P, Heal C, et al. Effect of promoting current local research activities on large monitors on the population's interest in health-related research: a randomised controlled trial. BMJ Open 2019;9:e028714. doi:10.1136/ bmjopen-2018-028714

- Prepublication history for this paper is available online. To view these files, please visit the journal online (http://dx.doi. org/10.1136/bmjopen-2018028714).

Received 20 December 2018 Revised 01 May 2019 Accepted 09 July 2019
Check for updates

(C) Author(s) (or their employer(s)) 2019. Re-use permitted under CC BY-NC. No commercial re-use. See rights and permissions. Published by BMJ.

For numbered affiliations see end of article.

Correspondence to

Professor Ronny Gunnarsson; ronny.gunnarsson@infovoice.se

\section{ABSTRACT}

Objective The objectives of this study were threefold: to estimate people's interest in health-related research, to understand to what extent people appreciate being actively informed about current local health-related research and to investigate whether their interest can be influenced by advertising local current health-related research using large TV monitors.

Design Randomised controlled trial using a stepped wedge design.

Setting The emergency department waiting room at two public hospitals in northern Queensland, Australia.

Participants Waiting patients and their accompanying friends and relatives in the emergency department waiting room not requiring immediate medical attention.

Interventions A TV monitor advertising local current health-related research.

Main outcome measures OR for the effect of intervention on changing the interest in health-related research compared with a control group while adjusting for gender, age and socioeconomic standard.

Results The intervention significantly increased the shortterm interest in health-related research with an $\mathrm{OR}$ of 1.3 $(1.1-1.7, p=0.0063)$. We also noted that being female and being older was correlated to a higher interest in healthrelated research

Conclusions This study found that proactive information significantly increased the general populations' interest in health-related research. There are reasonable set up costs involved but the costs for maintaining the system were very low. Hence, it seems reasonable that research-active organisations should give much higher priority to this type of activity.

Trial registration number ACTRN12617001085369

\section{INTRODUCTION}

Health-related research is the foundation for evidence-based medicine and is the driving force behind the remarkable progress in medicine seen in the last 150 years. Most health-related research is funded by the general population via three autonomous yet interlocking pathways: (1) taxes spent by federal,
Strengths and limitations of this study

- This is the first study of its kind aiming to actively increase the adult populations' interest in health-related research.

- The participation rate was high (69.3\%) despite the chaotic environment of an emergency department waiting room.

- A limitation of this study is that no long-term follow-up of the effect of the intervention was undertaken.

state and local governments on research, (2) a proportion of the cost of industry manufactured medicines and devices facilitating further R\&D and (3) by purchases from or donations to private non-profit organisations supporting research. ${ }^{1}$ Many research projects also require people to participate in clinical trials. Hence, it is reasonable to assume that the long-term survival of health-related research, and ultimately evidence-based medicine, requires the general populations' engagement. $^{2}$

Feeling informed about research seems to correlate with positive attitudes towards researchers ${ }^{3}$ but many people think they are not informed enough about current research. ${ }^{3}$ Levels of trust in researchers are high with $67 \%$ of Australians expressing high or very high trust. ${ }^{4}$ Fifty-six per cent of Australians requiring medical treatment state they would definitely or probably participate in a clinical trial, ${ }^{4}$ although only $45 \%$ would do so if they did not require medical treatment. ${ }^{4}$ The Research Australia opinion poll, however, only had a $9 \%$ response rate so the figures above may be unreliable.

Actively changing people's attitudes to increase the sales of commercial products has been well studied. ${ }^{5-8}$ Research on techniques 
to increase high school students interest in science often use an action based approach. ${ }^{9}$ There are only a few randomised controlled trials evaluating techniques to increase high school students interest in science. ${ }^{10} 11$ Studies targeting high school students focus on science in a broader perspective. There are to date, to the authors' knowledge, no studies presented in peer-reviewed scientific publications evaluating different approaches to influence the adult general populations' interest in health-related research.

This project aims (a) to estimate people's interest in health-related research, (b) to establish the extent to which people appreciate being actively informed about current local health-related research and (c) to discover if the level of people's interest can be influenced by proactively promoting local current health-related research using large TV monitors.

\section{METHODS}

This study received the Universal Trial Number (UTN) U1111-1199-3106. The full Human Research Ethics Committee approved study protocol can be downloaded from the clinical trial registration website. ${ }^{12}$

\section{Study design and logistics}

The study used an interrupted times-series design with multiple baseline design across cases, also named stepped wedge design. ${ }^{13}$ Two emergency departments (EDs), one in Cairns Hospital Australia and the other in Mackay Base Hospital Australia, were engaged. These two hospitals are located $736 \mathrm{~km}$ apart. Both sites served as controls during the first phase of the study. Randomisation determined that the Mackay ED first initiated the intervention between phases 1 and 2 while the Cairns ED remained as a control. Cairns ED initiated the intervention between phases 2 and 3, so both EDs were delivering the intervention during phase 3 .

\section{Setting and participants}

Data collection were undertaken by year 5 and year 6 medical students in the respective ED waiting rooms. Patients attending the ED were included if they met the following inclusion criteria:

- Patient self-presents to ED (excludes patients transported to the ED in an ambulance).

- Deemed by the ED reception staff to be non-urgent and capable of sitting in the waiting room (excludes patients with an illness requiring immediate attention).

- Being at least 18 years of age.

- Deemed by the medical student to have a reasonable understanding of English.

- Deemed by the medical student to have enough vision to be able to read the survey.

The medical students went to the ED waiting room when they were not rostered otherwise for lectures or clinical duties, thus were not seeing people in the ED in any capacity other than to administer the survey. The students approached all individuals sitting in the ED waiting room that seemed to be at least 18 years old irrespective of whether they were patients, friends or relatives. The student usually stayed for sessions of 1-3 hours approaching all new people entering the ED. Potential participants were left to sit for at least $10 \mathrm{~min}$ before being asked if they would participate in a research project answering a short survey. Those who agreed to participate answered a one-page survey anonymously and handed the survey back to the student.

\section{Randomisation and masking}

Both EDs were controls in phase 1, and both were active intervention in phase 3. Randomisation decided which hospital should give active intervention during phase 2. Two administrators observed and certified that first a decision was made that if a random number created in Excel was 0.0-0.4999999, Cairns Hospital would go first with active intervention. If it were 0.5-1.0 Mackay Base Hospital would go first. Author RG created, while the two witnesses were observing, a random number in Excel that turned out to be between 0.5 and 1.0. Hence, Mackay Base Hospital would go first. Patients attending the ED were not aware of the study until they were handed the written information, asked about participation and if consent were given, handed the survey. Further blinding was not possible due to the nature of this study.

\section{Intervention}

A large TV screen was installed in the waiting room in the ED during phase 2 or 3 . In Cairns ED waiting room, available space enabled fitting of a 55 inch screen while only a 40 inch screen could be installed in the Mackay ED. The TV screen is linked to a mini-Mac presenting an extract from an online project database of current local health-related research in the Cairns or Mackay area. ${ }^{14}$ The project database contained two fields targeted to laypersons, a title for laypersons and an abstract for laypersons. The project database also contained other fields such as scientific title and scientific abstract.

An administrator, with no clinical experience or expertise in research, first reviewed new descriptions of projects, and the researcher was asked to rephrase the information if it was deemed difficult to understand. Once the administrative person found the title and abstract understandable for laypersons it was cleared to be put up on the TV screens. By then, we assumed the researcher understood the principles for explaining to lay persons so any further editing by the researcher did not require the input of the administrative personnel. The project database automatically reminded the researcher by e-mail to update or confirm the information if no update was done. These reminders were sent out after seven, eight and 9 months of no update. Completed projects were not shown on the TV screen.

One project at a time was presented on the TV screen over $40 \mathrm{~s}$ (figure 1). The change between descriptions 


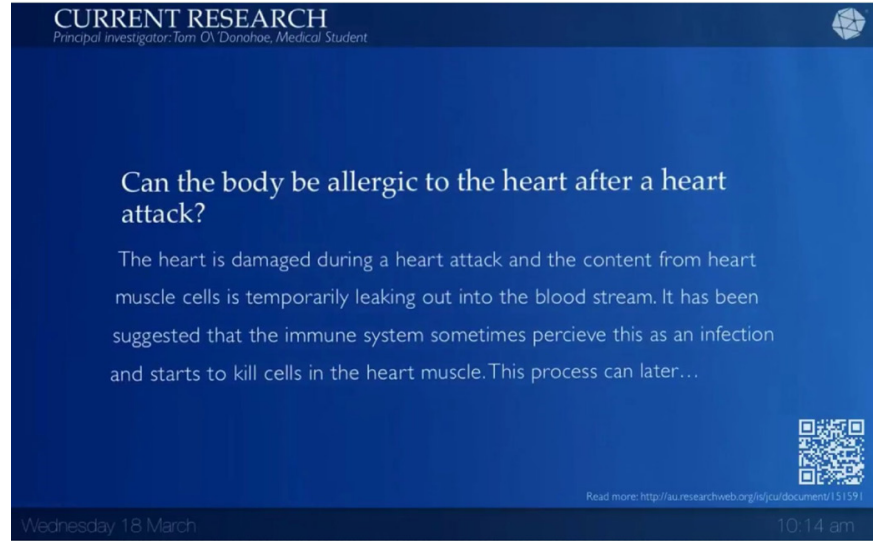

Figure 1 Example of presentation on the TV screen.

of different projects was done using a three-dimensional-like graphical rotation of texts. ${ }^{15} \mathrm{~A}$ batch of 30 current projects related to relevant organisations was randomly selected from the online project database and retrieved. They were shown one at the time, and after the last one, another batch was randomly selected, retrieved and shown. Hence, the information on the TV screens was constantly renewed and kept updated. Each project was presented with a title and short abstract for laypersons as well as a web-link and QR code to more information (figure 1). A sign beside the TV screen stated: 'This screen highlights current local research. If you see a project you believe is relevant to your health or that of someone close to you, feel free to discuss with your doctor. The doctor may decide to contact the researcher if relevant. Feel free to take a photo of any slide (but not of any people around).'

The projects registered in the database were research projects conducted by healthcare providers based in a hospital or primary healthcare clinic in north Queensland, Australia, or at James Cook University, Australia. All projects were related to health issues. It could be applied research or more theoretical laboratory research, all aiming to solve healthcare related issues. Each screen could be set to have a unique selection of projects related to a workplace or organisation and type of project. For the purpose of the study the two TV screens were programmed to show the same selection of current projects from the northern part of Queensland including the Cairns and Mackay region. None of these projects had, to the knowledge of the authors, any intention or strategy to proactively inform about their research other than in a direct targeted recruiting situation. There was no other information source about current local research provided in the participating ED waiting rooms.

\section{Outcome measures}

A simple one-page survey was handed out once to each participant which requested age, gender and postcode. Additionally, participants were asked: How interested are you in health and medical research? (Response alternatives: Not at all, somewhat, very). In study phases when the monitor was turned on the survey had the additional question: This waiting room has a TV displaying information about current health-related research in the surroundings. How interesting do you find the information? (Response alternatives: Not at all, somewhat, very).

The post code was translated to a percentile rank within Australia of the Socio-Economic Indexes for Areas (SEIFA) score. ${ }^{16}$ The SEIFA score is a ranking system developed by the Australian Bureau of Statistics, a government agency, and is a summary of a subset of Census variables which focuses on socio-economic advantage and disadvantage. This ranking varies between $0 \%$ and $100 \%$ where the average Australian is at $50 \%$. A high score indicates wealth while a low score represents poverty.

The outcome measures were (a) the responses to the question, 'How interested are you in health and medical research?' (b) the responses to the question, 'This waiting room has a TV displaying information about current health-related research in the surroundings. How interesting do you find the information?' and finally (c) the OR for the intervention to incur a change in the attitude 'How interested are you in health and medical research?'

\section{Monitoring of adverse events and safety procedures}

Due to the nature of this study, no adverse events were expected nor observed.

\section{Statistical analysis}

Descriptive statistics were calculated for outcome measures on age, gender, socio-economic status, interest in health-related research and appreciation of provided information. A multinomial logistic mixed model using a cumulative logit link for ordinal outcomes was used to estimate OR of an increase in one step (of the three-stepped scale) for factors correlating to an increased interest in health-related research. The interest in health-related research was the dependent variable while the study site was a random effect. Gender, age, socioeconomic index and the intervention were fixed effects. IBM SPSS statistics V.23 was used.

\section{Sample size calculation}

A sample size estimation was made for each of the aims:

a. Accepting a margin of error of $2.5 \%$ with a $95 \%$ confidence level and assuming that $80 \%$ are positive towards medical research requires 938 responses.

b. Accepting a margin of error of $2.5 \%$ with a $95 \%$ confidence level and assuming that $50 \%$ are positive to the automated information system for medical research requires 1428 responses.

c. Assuming a level of significance of $0.05,95 \%$ power, a two-tailed test and assuming that the proportion of patients being positive to medical research increases from $80 \%$ to $90 \%$ requires 341 surveys before and 341 surveys after the introduction of the automated presentation system.

We aimed to collect approximately 500 answered surveys in each phase, in total 1500 . 


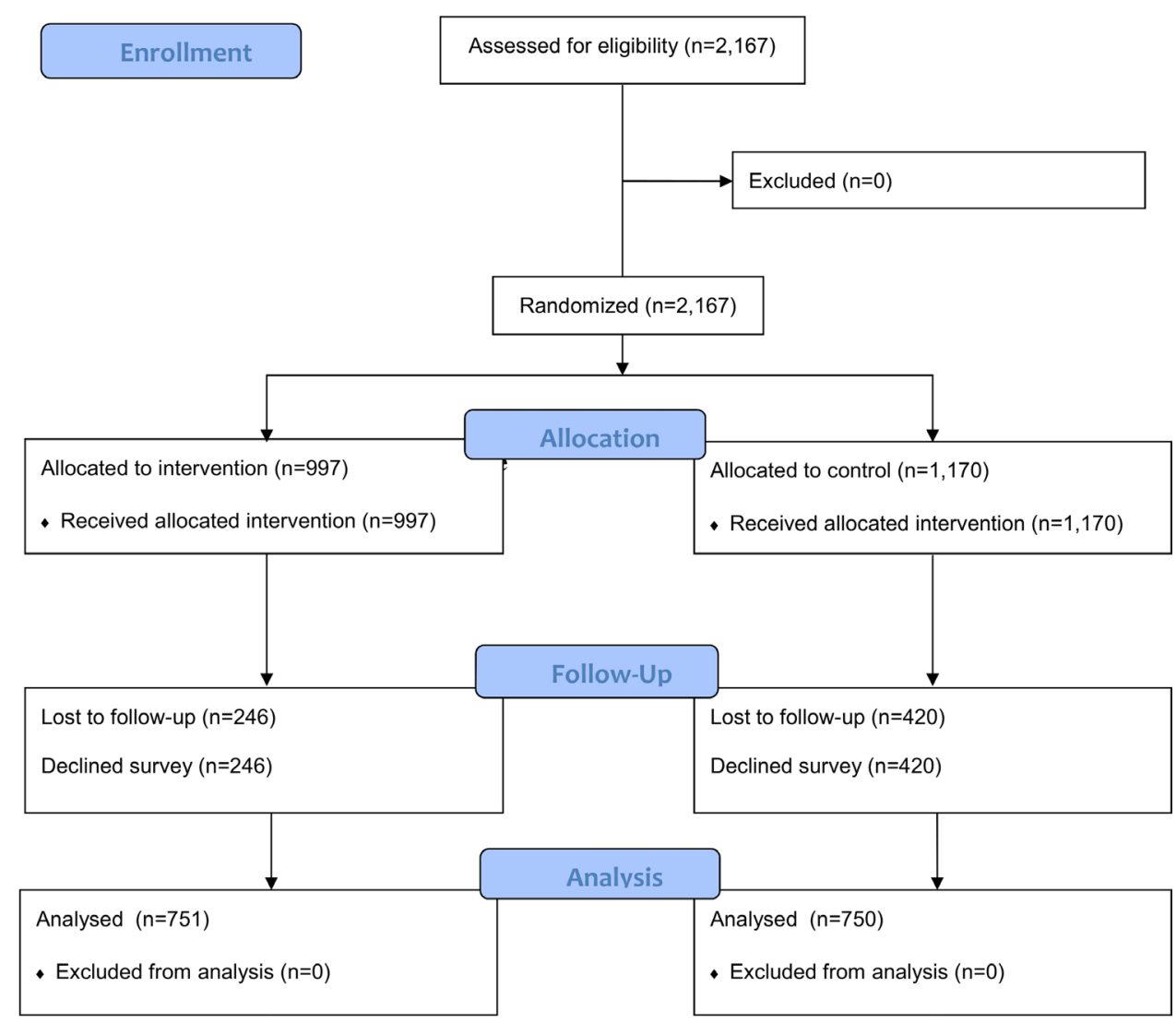

Figure 2 Consolidated Standards of Reporting Trials participant flow diagram.

\section{Patient involvement}

Patients were not involved in the development of plans for recruitment, design, outcome measures, or implementation of the study conduct. No patients were asked to advise on the interpretation or writing of results. The burden of the intervention was not assessed, but assumed to be low. We will pursue patient and public involvement in the development of an appropriate method for further dissemination.

\section{RESULTS}

Participants were recruited from the 23 May to 10 November 2017 at which point the target number of participants was reached. Of 2167 persons deemed to fulfil the inclusion criteria, 1501 (69.3\%) agreed to answer the survey (figure 2). Their interest in health-related research before the intervention was expressed as 'none' by $14 \%(106 / 750)$, 'somewhat' by $53 \%(396 / 750)$ and 'very interested' by $33 \%(248 / 750)$. The two groups were of similar age and gender (table 1$)$. However, the socioeconomic index differed slightly between study sites.

Being female and being older was correlated with a greater interest in health-related research (table 2). Persons in the intervention group expressed their interest in the TV displaying current local health-related research as 'none' in $18 \%(138 / 751)$, 'somewhat' in 54\% (407/751) and 'very interested' in $27 \%$ (206/751). The intervention of proactively promoting information about current local research significantly increased the interest in health-related research with an OR of $1.3(1.1-1.7, \mathrm{p}=0.0063)$ (table 2).

\begin{tabular}{lccc}
\hline Table 1 & Demographic information of those accepting participation & \\
& $\begin{array}{l}\text { Intervention group } \\
(\mathbf{n}=\mathbf{7 5 1 )}\end{array}$ & $\begin{array}{l}\text { Control group } \\
(\mathbf{n}=\mathbf{7 5 0 )}\end{array}$ & P value \\
\hline Site Cairns/Mackay & $250 / 501$ & $500 / 250$ & - \\
Female gender, n (\%) & $422(56)$ & $415(55)$ & 0.76 \\
Age in years, mean (SD) & $42(17)$ & $41(17)$ & 0.29 \\
$\begin{array}{l}\text { Socioeconomic index, }{ }^{*} \text { mean } \\
\text { (SD) }\end{array}$ & $56(15)$ & $51(17)$ & $3.3 \times 10^{-10}$ \\
\hline
\end{tabular}

*An Australian index of socioeconomic standard linked to postal code. Varies between 0 (lowest standard) and 100 (best standard). The Australian average is 50 . 


\begin{tabular}{|c|c|c|c|}
\hline$n=1486$ & Type of effect & $P$ value & Adjusted OR* \\
\hline Site Cairns/Mackay & Random & 0.48 & $0.85(0.052-14)$ \\
\hline Increasing age (one decade) & Fixed & $6.6 \times 10^{-8}$ & $1.2(1.1-1.3)$ \\
\hline $\begin{array}{l}\text { Increasing socioeconomic } \\
\text { index† }\end{array}$ & Fixed & 0.61 & $1.0(0.99-1.0)$ \\
\hline
\end{tabular}

${ }^{*}$ A multinomial logistic mixed model using a cumulative logit link for ordinal outcomes was used to estimate OR of an increase in one step (of the three-stepped scale) for factors correlating to an increased interest in health-related research. All independent variables were entered simultaneously in the model. 1486 participants had a complete data set and could be included.

†An Australian index of socioeconomic standard linked to post code. Varies between 0 (lowest standard) and 100 (best standard).

\section{DISCUSSION}

This study found that proactively promoting information about current local health-related research is likely to increase the interest among the general population irrespective of age, gender and socioeconomic standard.

\section{Increasing the general populations' engagement in health- related research}

This study found that $86 \%$ of the adult population expressed they were somewhat or very interested in current local health-related research. This is similar to previous results from the UK. ${ }^{3}$ Most people in the intervention group $(81 \%)$ found the TV screen to be somewhat or very interesting. It was beyond the scope of this study to clarify why the TV screens might have been perceived as interesting. This would be a suitable topic for a follow-up study using a qualitative approach.

This is, to our knowledge, the first scientific study seeking to increase the general population's interest in health-related research by proactively promoting information about local current research activities. This study found that proactive providing information significantly increased the interest in health-related research. Whether the TV screen was turned on or off was the only change made between groups in this randomised controlled trial. We could prove a statistical difference between groups, rejecting the null hypothesis that turning on or off the TV screens makes no difference. The most plausible explanation is that the TV screens made a difference.

There are some reasonable setup costs, but the costs for maintaining technical operation of the system were very low. Hence, it seems reasonable that research-active organisations should give much higher priority to this type of activity given the magnitude of the effect with an OR of 1.3.

This study only investigated an immediate effect of proactively promoting information about local current research activities. The idea with the system is to run indefinitely, preferably in multiple locations, allowing for repeated exposure and this is likely to create a long-term effect on peoples' interest. However, a study properly investigating the long-term effect of repeated exposure to this type of proactive information has never been done.
The results from this study showing an immediate effect may provide the incentive for a follow-up study focusing on long-standing effects and impact on recruitment to clinical trials.

Exposing people to current research is a form of passive knowledge transfer that, according to this study, may have an effect on their interest in health-related research. However, people often form opinions by means other than acquiring knowledge and subsequent rational thinking. ${ }^{2}$ Hence, to further build from knowledge transfer and understanding one should introduce actions facilitating dialogue around and engagement in health-related research. ${ }^{217}$ It was beyond the scope of this study to investigate effects of actions aimed to facilitate dialogue and engagement.

\section{Practical aspects}

Our experience was that a fair proportion of researchers did not typically describe their research project in plain English without using terminology requiring expert knowledge. Hence, the initial check of new registrations in the project database performed by a non-clinician administrative person was vital. It is unlikely that this project would have shown a change in attitudes among laypersons without this simple check and subsequent feedback to researchers.

We also noted that a fair proportion of researchers stated the wrong workplace or organisation they were affiliated with such that administrators also helped researchers with accuracy in this regard. This is somewhat relevant since each TV selected projects related to nearby workplaces or organisations.

We did encounter the situation that a few people in the waiting rooms tried to change the settings on the TV, especially during major sports events. Hence, it is recommended to use a TV monitor where settings can be locked. The EDs in this study regularly cut power to test redundancy systems. Hence, we soon learnt that the equipment should also be set up so it can start up unattended after a power outage.

\section{Gender and age}

This study found female gender and increased age are linked to more interest in health-related research. This 
is consistent with a European study finding that men and younger adults are more interested in science and technology but women and older persons are more interested in medical and health-related research. ${ }^{3} 18$

\section{Methodological aspects}

The response rate of $69.3 \%$ is deemed acceptable given the sometimes chaotic environment of an ED waiting room. A weakness of the study is that we have no information about the $30.7 \%$ who chose not to participate.

The number of questions was deliberately kept at a minimum to enable a reasonable response rate to the survey. Hence, information about possible confounding factors such as ethnicity, education, comorbidities and prior exposure to information about health-related research was not obtained, and their relative importance could therefore not be estimated. However, the randomised design did significantly reduce the risk for these potentially confounding factors to be the sole explanation to the finding of an effect by turning on the TV monitors.

The groups differed in socioeconomic level, and this may be explained by Mackay ED being randomised to start before Cairns ED. This means Mackay ED had one period of control and two periods of active intervention while Cairns ED had the opposite. Cairns is located more remotely in far north Queensland with a higher proportion of Aboriginal and Torres Strait Islander people compared with Mackay. Several of the Aboriginal and Torres Strait Islander people attending the ED in Cairns come from remote communities in the Cape York Peninsula where the socioeconomic level is low. Hence, this difference is expected and was adjusted for in the inferential statistical analysis. Both groups were quite close to 50 in the socioeconomic index indicating that the sample included resembles the average Australian population.

Any crossover effect between the two sites where family or friends may have been exposed to the intervention at the other site, could potentially have reduced the ability to find an effect of the TV screens (increased the risk of a type II error) but not falsely show an effect (type I error). A crossover effect between the two sites was deemed highly unlikely since the two hospitals were located 736 $\mathrm{km}$ apart. Hence, a crossover effect is unlikely in this study, and if there was any the real effect of the TV screens would be larger than we could show in this study.

There is a multitude of surveys measuring different aspects of attitudes related to science. ${ }^{19} 20$ The aspect most relevant to this study was general attitudes of appreciation towards health-related science. When seeking a survey instrument measuring this aspect of attitude towards science with the highest validity and reliability, this was, according to Blalock et $a l^{19}$ the Attitude Toward Science in School Assessment (ATSSA). ${ }^{21}$ This instrument has 14 items and is targeted to high school students in science class. To work in an ED situation something much simpler and more general would be required. Hence, we used a single question 'How interested are you in health and medical research' with a three-stepped Likert scale. This question, which resembles several items in the ATSSA, has been used in previous population surveys. ${ }^{18}$

\section{Generalisability}

The overall interest in health-related research found in this study is similar to previous population surveys. The finding that female gender and higher age are related to a greater level of interest is also consistent with findings of previous studies. ${ }^{3} 18$ The demographic characteristics, including socioeconomic status of included participants, are similar to the Australian average. All this suggests that this study included a population representative of the average population in a high-income country. Hence, we can expect that the finding that the intervention is effective can reasonably be generalised to all of Australia. Readers outside of Australia have to decide if these findings are applicable also in their country.

\section{CONCLUSIONS}

Proactively promoting information about current local health-related research to the general population using large TV screens increased their interest in health-related research. This can potentially be of importance when promoting evidence-based medicine or recruiting patients to a trial. Hence, it seems reasonable that research-active organisations adopt a much more proactive approach to informing the general public. Future research could clarify if this increased interest is linked to an increased appreciation of funding for research or an increased motivation for participating in research.

\section{Author affiliations}

${ }^{1}$ Primary Health care, Public Health and Community Medicine, Institute of Medicine, the Sahlgrenska Academy, Gothenburg, Sweden

${ }^{2}$ Research and Development Primary Health Care, Research and Development Center Södra Älvsborg, Region Västra Götaland, Boras, Sweden

${ }^{3}$ Emergency Department, Cairns Hospital, Queensland Health, Cairns, Queensland, Australia

${ }^{4}$ College of Medicine and Dentristry, James Cook University, Cairns, Queensland, Australia

Acknowledgements A sincere thanks to the following medical students participating in collecting surveys: Pauline Lau (year 5), Mrinal Pawar (year 6), Georgina Spalding (year 6), Nethmee Gunadasa (year 4), Karen Huynh (year 6), Kanishk Chaudhary (year 6), Yng Or (year 6), Krysti Rosmalen-Brinkley (year 6), Thomas Whittaker (year 6).

Contributors RG was solely responsible for conception, design and statistical analysis. RG was the lead in planning, writing study protocol, ethics application, conduct, interpretation of data and writing the manuscript with assistance from PC, $\mathrm{CH}$ and JB. RG was the lead in acquisition of data with assistance from JB.

Funding Funding for this project came from the College of Medicine and Dentistry at James Cook University, Australia and Cairns Hospital Foundation, Cairns, Australia.

Competing interests The online project database used in this study was Researchweb. RG was responsible for the development of the Researchweb system between 2000 and 2011 when it was developed within the Vastra Gotaland region (a government-run healthcare provider in the south-western part of Sweden). The Researchweb system was transferred from the Vastra Gotaland region to a limited liability company in February 2012. There have never been any financial links or remunerations between the limited liability company and RG, nor is there (or will 
ever be) any written or verbal agreements about any future remunerations from this company to RG.

Patient consent for publication Not required.

Ethics approval The Townsville Hospital and Health Service Human Research Ethics Committee (HREC/15/QTHS/174).

Provenance and peer review Not commissioned; externally peer reviewed.

Data availability statement Data are available in a public, open access repository. The full data set is available at: https://doi.org/10.5061/dryad.278nj37

Open access This is an open access article distributed in accordance with the Creative Commons Attribution Non Commercial (CC BY-NC 4.0) license, which permits others to distribute, remix, adapt, build upon this work non-commercially, and license their derivative works on different terms, provided the original work is properly cited, appropriate credit is given, any changes made indicated, and the use is non-commercial. See: http://creativecommons.org/licenses/by-nc/4.0/.

\section{REFERENCES}

1. Bloom F, Randolph M. Funding health sciences research: a strategy to restore balance. Washington (DC: National Academic Press (US), 1990.

2. Simis MJ, Madden $\mathrm{H}$, Cacciatore $\mathrm{MA}$, et al. The lure of rationality: why does the deficit model persist in science communication? Public Underst Sci 2016;25:400-14.

3. Public attitudes to science 2011. Summary report. ipsos mori and the British science association (BSA), 2011

4. Roy Morgan Research. Australia speaks! - Research Australia opinion polling 2017, 2017. Available: https://researchaustralia.org/reports/ public-opinion-polling-2017/

5. DeJong C, Aguilar T, Tseng C-W, et al. Pharmaceutical industrysponsored meals and physician prescribing patterns for Medicare beneficiaries. JAMA Intern Med 2016;176:1114-22.

6. Smith LA, Foxcroft DR. The effect of alcohol advertising, marketing and portrayal on drinking behaviour in young people: systematic review of prospective cohort studies. BMC Public Health 2009;9:51.

7. Lovato $\mathrm{C}$, Watts A, Stead LF, et al. Impact of tobacco advertising and promotion on increasing adolescent smoking behaviours. Cochrane Database Syst Rev 2011;12.
8. Costea D, Carter F, Chou S-Y, et al. Is advertising effective or not? Evidence from the pharmaceutical market. NMIMS Management Review 2012;XXII.

9. Vartuli C. Increasing high school students interest in science: an action research study. Connecticut: University of Bridgeport, 2017.

10. Hulleman CS, Harackiewicz JM. Promoting interest and performance in high school science classes. Science 2009;326:1410-2.

11. Wilson CD, Taylor JA, Kowalski SM, et al. The relative effects and equity of inquiry-based and commonplace science teaching on students' knowledge, reasoning, and argumentation. J Res Sci Teach 2010;47:276-301.

12. Gunnarsson RK. The effect of providing information on health related research in a hospital waiting room on interest and attitudes to research amongst patients and visitors: Australian New Zealand clinical trials registry (ANZCTR), 2017. Available: https://www.anzctr. org.au/Trial/Registration/TrialReview.aspx?id=373306\&isReview=true

13. Biglan A, Ary D, Wagenaar AC. The value of interrupted timeseries experiments for community intervention research. Prev Sci 2000;1:31-49.

14. Gunnarsson RK. Collaborative advantage research database (CARD), 2018. Available: http://au.researchweb.org/is/jcu/help/projectdatabase

15. Gunnarsson RK. Presenting current local research projects to the general public, 2018. Available: https://www.youtube.com/watch?v= nsL3CBn9UrE

16. 2016 SEIFA by postal area code (Poa), 2016. Available: http://stat. data.abs.gov.au/Index.aspx?DataSetCode=ABS SEIFA2016 POA\#

17. Stilgoe J, Lock SJ, Wilsdon J. Why should we promote public engagement with science? Public Underst Sci 2014;23:4-15.

18. Poll highlights Europeans' interest in health research: European Commission, 2007. Available: https://cordis.europa.eu/news/rcn/ 28356 en.html

19. Blalock CL, Lichtenstein MJ, Owen S, et al. In pursuit of validity: a comprehensive review of science attitude instruments 1935-2005. Int J Sci Educ 2008;30:961-77.

20. Besley JC. The state of public opinion research on attitudes and understanding of science and technology. Bull Sci Technol Soc 2013;33:12-20.

21. Germann PJ. Development of the attitude toward science in school assessment and its use to investigate the relationship between science achievement and attitude toward science in school. J Res Sci Teach 1988;25:689-703. 